\title{
A STUDY ON IMPACT OF SOCIAL MEDIA ON ACADEMIC PERFORMANCE
}

\author{
Gowtham Aashirwad Kumar \\ Research Scholar \& Assistant Professor, Department of Management Studies, \\ Bharath Institute of Higher Education and Research, Chennai, India
}

\section{Dr A Ravi Kumar}

Research Supervisor \& Associate Professor, Department of Tourism and Hotel Management, Bharath Institute of Higher Education and Research, Chennai, India

\begin{abstract}
In latest years era has attempted to fulfill its role in helping humanity leading to the good sized medium of interaction within the social world in addition to in teaching and learning. Over the years those in higher training has discover the exciting possibilities new technology carry to institutions, educators and students. Technology has modified the manner people have interaction and has brought about the emergence of an open social platform such as social media that allows the population of this planet earth to connect with each other making the sector a international village. Social media together with Face book, Twitter, Google Plus, and Flickr, are getting used in gaining knowledge of for the purpose of convenient communiqué with different college students and doubtlessly with others out of doors the class such as students of the same topic and subject experts. Web based life utilization among medicinal understudies has additionally seen enormous surge. It is giving therapeutic educationists new ideal models in instructing learning movement. A few situations currently supplement customary up close and personal preparing with web based life workshops, online little gathering work, and even one-on-one coaching. Such exercises in India are restricted right now albeit ongoing information have demonstrated evolving patterns.
\end{abstract}

Keywords: Web, People, Online Tools, Feedback, facebook.

Cite this Article: Gowtham Aashirwad Kumar, Dr A Ravi Kumar, A Study on Impact of Social Media on Academic Performance, International Journal of Management (IJM), 11 (1), 2020, pp. 15-20.

http://iaeme.com/Home/issue/IJM?Volume $=11 \&$ Issue $=1$

\section{INTRODUCTION}

With growing penetration of the Internet in trendy world, SNS is turning into an accepted aspect of social life. A 2013 survey discovered that $73 \%$ of US adults get entry to SNSs. India had an estimated 350 million Internet users in 2015 and is likewise recording a huge increase 
in social media use. This rapid increase gives new possibilities for self-getting to know and options to standard classroom- or library-primarily based educational activity. The flexibility of on-line tools lets in customization of gaining knowledge of to fit learners' needs. Students actively participating in a blog-based dialogue discussion board have shown better grades than college students who posted much less often. Peer evaluation of posts and feedbacks can overcome capacity worries like sharing erroneous information. Social media usage among scientific students has also witnessed exquisite surge. It is providing medical educationists with new paradigms in teaching-gaining knowledge of activity. Some environments now supplement traditional face-to-face training with social media seminars, on-line small group work, and even one-on-one mentoring. Such sports in India are confined on the moment despite the fact that recent facts have indicated changing trends.

\section{REVIEW OF LITERATURE}

Boyd and Ellison (2007) ${ }^{1}$ characterized interpersonal organization destinations as open electronic administrations that enable clients to accumulate an individual profile, distinguish other clients with whom they've an association, peruse and respond to postings made by different clients on the site, and send furthermore, get messages either secretly or openly. These digital administrations enable human beings to construct a open or semi-open profile inside a restrained framework. Among the most well known are Facebook and LinkedIn.

Tapscott and Williams (2007) ${ }^{2}$ contend that, youthful individuals 'are not substance to be latent customers, and steadily fulfill their longing for decision, accommodation, customization, and manipulate through structuring, creating, and disseminating items themselves.

Chati et al., (2010) ${ }^{\mathbf{3}}$ Basically, learning may be visible asan singular capacity to companion with precise data hubs and resources as and while required. Subsequently information potential could request maintaining and upkeep of those associations.

Douglas Thomas and John Seely Tans (2011) ${ }^{4}$ depiction of an innovation upgraded new culture of Learning that says, learning is based around standards of aggregate investigation, play and advancement as opposed to individualized guidance, it could be contended that web based life bolsters the part of information utilization and development that are very distinctive to the epistemological guideline of formal training and individual guidance just as sounding with as of now elegant constructivist and socio social learning speculations.

\section{OBJECTIVES OF STUDY}

\subsection{Primary Objective}

To survey the online existence utilization and dissect self-noticed sway on scholastic execution and relational relations.

\subsection{Secondary Objective}

- To analyze the pervasiveness of web based life use among university understudies of mass correspondence.

- To contemplate the effect of web based totally lifestyles on relational relationship of university understudies of mass correspondence.

- To reflect on consideration on the constructive results of internet based existence use at the relational dating of college understudies of mass correspondence.

\section{SCOPE OF THE STUDY}

The investigation become led to assess the impact of on-line existence on understudies' scholastic execution. The examination limited uniquely on factors of online networking that 
the specialists expected that has impacts of respondents' scholarly exhibition. These elements are respondents' front to web, use, discernment through web-based networking media, and their recurrence of making use of it.

\section{RESEARCH DESIGN}

Research configuration is association between what has been set up and what could possibly be done the lead of the review for the acknowledgment of the target. The examination configuration worn in this investigation was illustrative research structure.

Spellbinding examination is utilized to depict distinction of a populace or marvel being considered. It doesn't react inquiries concerning how/when/why the character happened.

\section{DATA COLLECTION}

\subsection{Primary Source}

Primary data alludes to the information that was gathered direct, in a straight line from the source. This comprised primarily of meetings and talks with the directors, shoppers and further more incorporates direct perception.

Primary data was gathered through organized undisguised survey.

\subsection{Secondary Source}

Secondary data alludes to the information that was before gathered by others for another reason. It incorporates:

- Internet.

- Manuals and Research Papers and Books.

\subsection{Sampling Method}

Optional information alludes to the information that was before gathered by others for another reason. It incorporates:

- Internet.

- Manuals and Research Papers and Books.

\subsection{Convenience Sampling}

Convenience Sampling (otherwise called snatch inspecting, unintentional examining, or opportunity testing) is a sort of non-likelihood testing that includes the example being stressed from that piece of the populace that is near hand.

\subsection{Statical Tools}

\section{Sample Size}

A significant choice that needs to taken is embracing the examining method is about the size of the example. Size of the example implies the amount of examining.

The sample size chose for this examination is 100 .

Test Size $=[$ Z2 X P X Q $] /$ E2

The sampling technique embraced for this examination was convenient sampling method. It was adjusted to 100 .

\subsection{Population Size}

Every one of the things under idea in any field of request make up a 'universe' or 'populace'. A total subtleties of the considerable number of things in the 'populace' is known as a registration request. 


\section{CHI SQUARE TEST}

A chi-squared test, additionally alluded to as a chi square test, is any factual theory test wherein the inspecting dissemination of the test measurement is a chi-square appropriation when the invalid speculation is valid. Chi-squared tests are frequently build from a whole of squared mistakes, or through the example fluctuation. Test figures that pursue a chi-squared dissemination emerge from a supposition of autonomous ordinarily circulated information, which is legitimate as a rule because of as far as possible hypothesis.

Chi Square Test $=\sum[(\mathrm{O}-\mathrm{E}) 2 / \mathrm{E}]$

\section{LIMITATIONS OF THE STUDY}

Within Chennai City

\subsection{Data Analysis and Interpretation}

Table 1 Students Used Social Media

\begin{tabular}{|c|l|c|c|}
\hline S.NO & \multicolumn{1}{|c|}{ PARTICULARS } & $\begin{array}{c}\text { NO OF } \\
\text { RESPONDENTS }\end{array}$ & PERCENTAGE \\
\hline 1 & $\begin{array}{l}\text { Conversation with Social } \\
\text { Media }\end{array}$ & 25 & $25 \%$ \\
\hline 2 & Facebook & 35 & $35 \%$ \\
\hline 3 & Whatsapp & 40 & $40 \%$ \\
\hline 4 & Wechat & 0 & $0 \%$ \\
\hline & Total & 100 & $100 \%$ \\
\hline
\end{tabular}

\section{Inference}

Most of the students used whatsapp. $35 \%$ of students used facebook, $25 \%$ of students used conversation and only $0 \%$ of students used wechat.

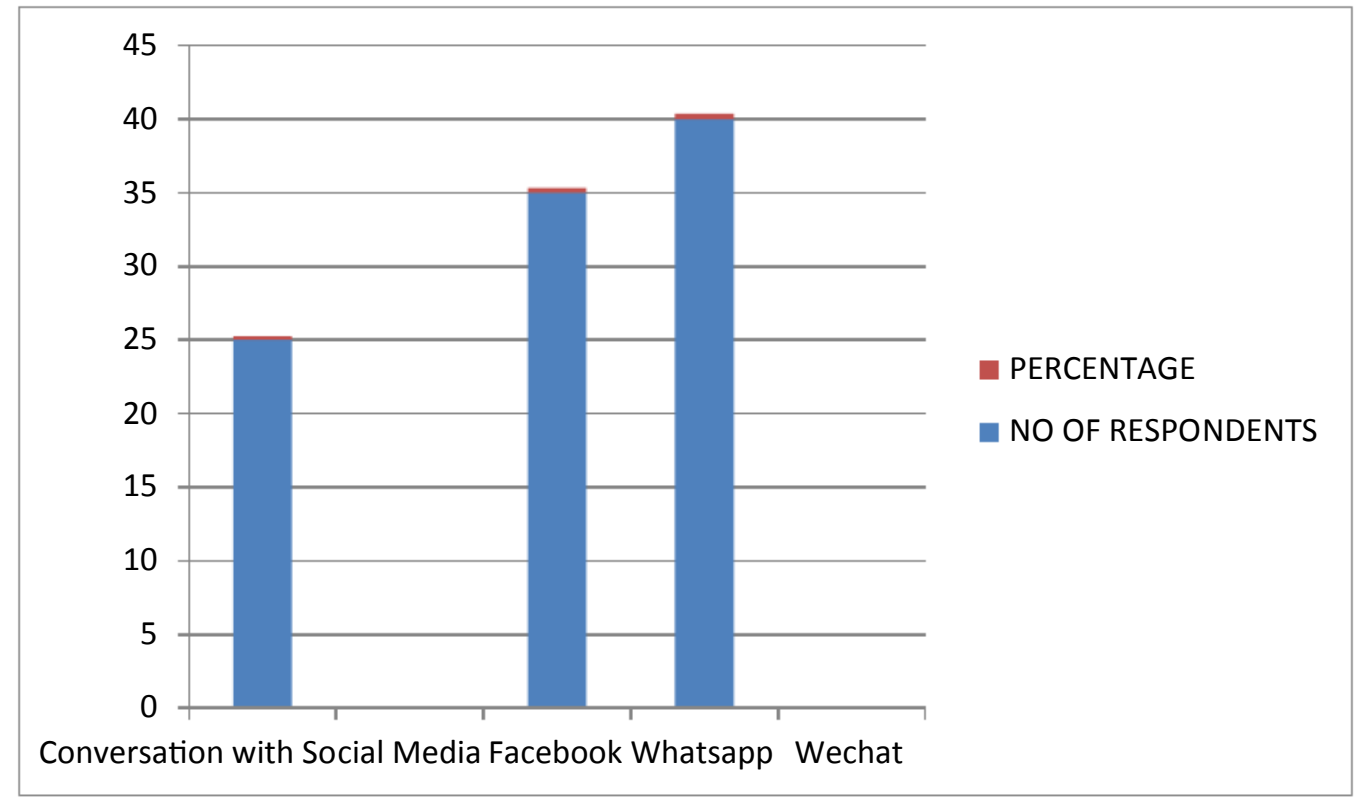

Chart 1 Students Used Social Media 
Table 2 Apparent Result on Educational Presentation and Physical and Communal Well-Being:

\begin{tabular}{|c|l|c|c|}
\hline S.NO & \multicolumn{1}{|c|}{ PARTICULARS } & NO OF RESPONDENTS & PERCENTAGE \\
\hline 1 & Educational Presentation & 10 & $10 \%$ \\
\hline 2 & Material Comfort & 60 & $60 \%$ \\
\hline 3 & Public Happiness & 20 & $20 \%$ \\
\hline 4 & Others & 10 & $10 \%$ \\
\hline & Total & 100 & $100 \%$ \\
\hline
\end{tabular}

\section{Inference}

Most of the students used Material Comfort. 20\% of students said Public Happiness, 10\% of students said both others and educational presentation.

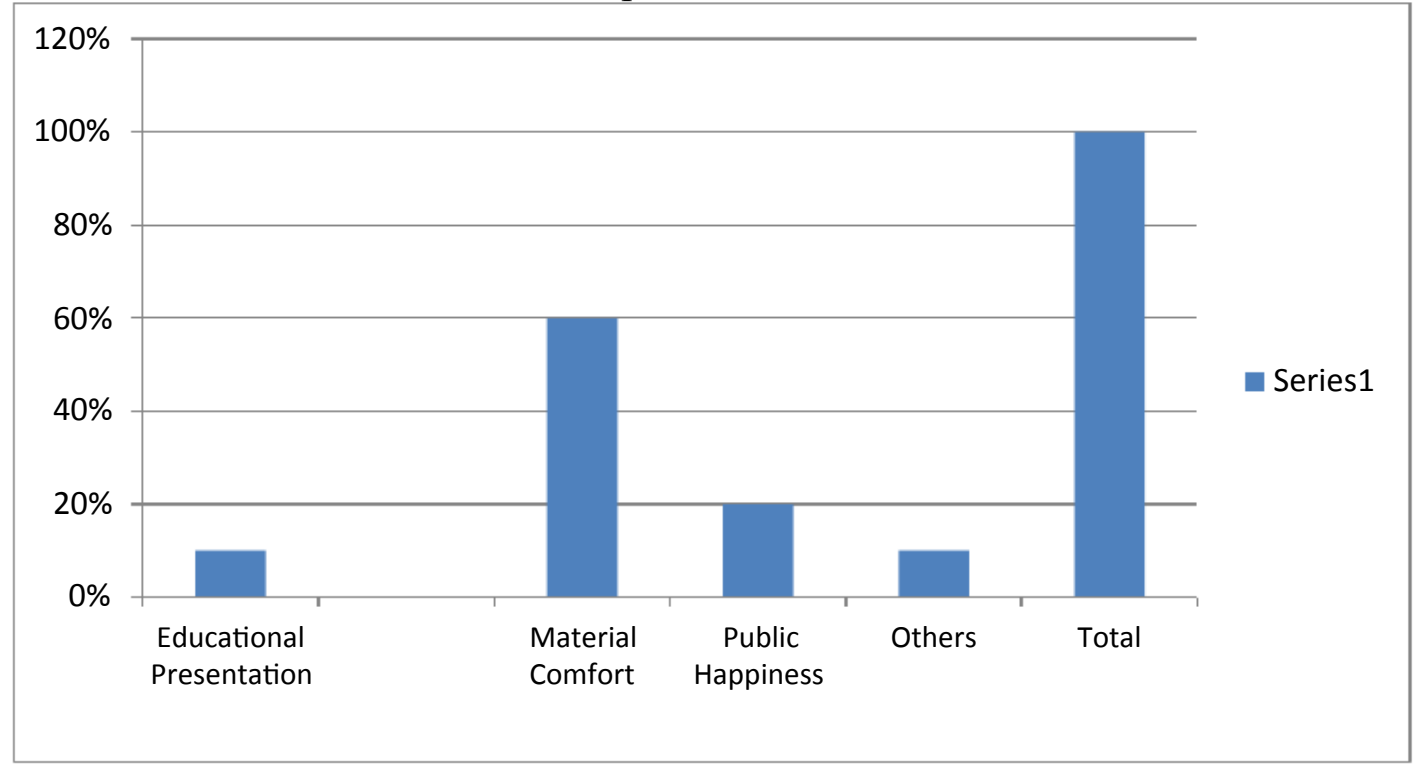

Chart 2 Apparent Result on Educational Presentation and Physical and Communal Well-Being

\section{CHI - SQUARE TEST}

Table 3 Chi Square Test For Students Used Social Media

\begin{tabular}{|c|c|}
\hline 25 & 35 \\
\hline 40 & 0 \\
\hline
\end{tabular}

\subsection{Null Hypothesis}

There is no significant change among students usage of social media.

\subsection{Alternative Hypothesis}

There is significant among students usage of social media.

Table 4

\begin{tabular}{|c|c|c|c|c|}
\hline $\mathrm{O}$ & $\begin{array}{c}\mathrm{E}=\text { R.T X C.T } \\
\text { /G.T }\end{array}$ & $(\mathrm{O}-\mathrm{E})$ & $(\mathrm{O}-\mathrm{E})^{2}$ & $(\mathrm{O}-\mathrm{E})^{2} / \mathrm{E}$ \\
\hline 25 & 39 & -14 & 196 & 5.025 \\
\hline 35 & 21 & 14 & 196 & 9.333 \\
\hline 40 & 26 & 14 & 196 & 7.538 \\
\hline 0 & 14 & -14 & 196 & 14 \\
\hline & & & TOTAL & 35.896 \\
\hline
\end{tabular}


$\chi^{2}=(\mathrm{O}-\mathrm{E})^{2} / \mathrm{E}$

$\chi^{2}=35.896$

Calculated Value (C.V) $=35.896$

\subsection{Degrees of Freedom}

$$
\begin{aligned}
& \mathrm{V}=[\mathrm{r}-1][\mathrm{c}-1] \\
& \mathrm{V}=[2-1][2-1] \\
& \mathrm{V}=1 \mathrm{X} 1 \\
& \mathrm{~V}=1
\end{aligned}
$$

Table Value $[\mathrm{T} . \mathrm{V}]=3.84$

Calculated Value $[\mathrm{C} . \mathrm{V}]=35.896$

Therefore, Calculated Value (C.V) $>$ Table Value (T.V)

Therefore, it is significant

Therefore, Null Hypothesis is forbidden and alternative hypothesis is recognized.

\section{FINDINGS \& SUGGESTIONS}

- Most of the students used whatsapp.

- Most of the students used Material Comfort.

\section{CONCLUSION}

Most of the Students Used Whatsapp . Most of the Students Used Material Comfort. Social media utilization for academic functions is high among Medical, Paramedical, and Nursing College Students in our institution. Most College Students. It from Social Networking on Instructional the front and are aware of its high quality as well as negative influence on social and interpersonal relations. Hence, coaching curriculum have to comprise learner-centric modules thru social media for greater effect on scholar wellbeing.

\section{REFERENCES}

[1] Wikipedia Contributors. Social Networking Service. The Free Encyclopedia; 22 October, 2017. Available from: https://www.

en.wikipedia.org/w/index.php?title=Social_networking_service and oldid=806485975. [Last accessed on 2018 May 01].

[2] Lunden I. 73\% of US Adults use Social Networks, P interest Passes Twitter in Popularity, Facebook Stays on Top. Available from: https://www.techcrunch.com/2013/12/30/ pew-social-networking/. [Last accessed on 2018 May 01].

[3] Simon K. Digital, Social and Mobile in India; 2015. Available from: http://www.wearesocial.com/uk/special-reports/ digital-social-mobile-india-2015. [Last accessed on 2018 May 01]. 